data. There was some ambivalence in the group about the adequacy of existing data sources in terms of the reliability of the respondent supplied information, and the categories used (although none made a case that adequate aggregate classifications could not be developed from available data). For example, in the case of service industries, apparent changes in trends often reflected a change in categorisations of types of work rather than real changes. By the same token, the nature of certain types of work may change but without a commensurate change in name. Consider for instance the changing nature of clerical work.

The reliability of the linkages between different data-collections was also regarded as an obstacle to research. Many of these concerns have been alleviated in recent years (through New Zealand Standard Industrial Classification (N.Z.S.I.C.) and New Zealand Standard Occupational Classification (N.Z.S.O.C.)) although much work on retrospective reconstruction remains to be done.

A larger problem is the thinness of available data in the face of wide complexity and rapid change. Some form of fairly frequently collected (household) labour force survey seems needed not only to measure the extent of unemployment, but also to monitor a wide range of changes in job conditions, flows, satisfactions and consequences.

\title{
DISCUSSION
}

Grimes asked whether the role of migration in filling in skill needs was discussed. Smith indicated that it was not but noted that Government just allowed technical change to take place and he felt there was a need to plan this more carefully so as to minimize retraining needs. An example was the Think-Big projects where he felt the need for skills could have been anticipated and more local labour used.

Williams questioned the meaning of technical change; did it mean single changes or incremental changes? Did it mean retraining or deskilling? The assumption in the group report was that it was the former.

\section{GROUP 3. ETHNIC GROUPS AND THE LABOUR MARKET}

Members : John Hicks, Craig Hill, David Imray, Richard Sawrey.

Major questions

Five main questions were identified :

(1) What are the appropriate ethnic groupings to be considered?

(2) What type(s) of disadvantage do these groups experience in employment, for example in income and occupational mobility?

(3) Does the disadvantage result from "cultural rejection" by the groups or from discrimination?

(4) What role is played by lack of education, training and experience in 
40.

generating disadvantage?

(5) What can be done in the way of positive action programmes?

Existing answers $\operatorname{Re}(1)$ and (2), many of the above questions are currently under study by Department of Statistics. Major issues include self-determination, cultural affiliation and racial origins. Re (3), work undertaken at the Industrial Relations Centre suggests that the major disadvantage results from occupational segregation. Re (4), there appears to be no known work being undertaken on this issue. $\operatorname{Re}(5)$, the Department of Statistics has reported some analysis relating to this issue. Nevertheless this is clearly the most difficult question to be answered. Not only do the problems need to be clearly identified but politically acceptable policy solutions must be formulated. Although a number of ideas exist no clear plan of action has yet begun to emerge.

Questions of highest priority Those who are sympathetic to the problem of ethnic disadvantage in employment are generally convinced that the problem arises primarily because of racial discrimination in the work-place. However this needs to be demonstrated scientifically in order to gain the support of those who have, to this point, given little consideration to the problem. It is accepted that bigots are unlikely to change their views regardless of the evidence presented.

Major obstacles to this research (1) Identifying who should do the research and how it ought to be funded. (2) Lack of information. Data currently collected is often not appropriate because it has been collected for a specific purpose unrelated to the study of ethnic disadvantage. The reliability of data is therefore a problem. Data on psychological issues, such as the contribution of family and cultural support to an individual's well-being will be difficult to collect.

(3) Public and political opposition to research into issues of race. (4) Raising the level of priority given to research on race - especially amongst researchers.

other observations Research should not be presented in an aggressive or political manner in order to avoid a similar response (usually anti) by those who are responsible for making policy decisions.

\section{DISCUSSION}

Brown began the discussion by observing that discrimination was one among several differentials observed in the labour market and that ethnic variations also exist in non-market work. Shipley noted that discrimination led to a focus on the wider society and that this was appropriate because it meant that greater attention was paid to non-Maori institutions in particular. Imray argued for recognition that sometimes discrimination was legitimate, for example in the mode1ling of clothes where sex "discrimination" was expected. Because of difficulties with the use of the term "discrimination" in such a context he felt the term prejudice more 
accurately described the phenomena under discussion.

Rose noted that the question of the research objective was important. There was a tendency to examine the question of discrimination (prejudice) by focussing on ethnic groups whereas the agency itself should be the object. Brosnan followed this up by pointing out that there was a need to go to different parts of the agency because prejudice can occur at different levels, from managers, from other workers, and from customers.

\section{GROUP 4. MIGRANT LABOUR AND POLICY}

Members : Grant Andrews, Arthur Grimes, John Martin, David Pearson.

\section{Major questions}

Two broad areas of research were pinpointed. The first was an examination of migrant workers, that is transient workers who are not integrated into the social context of the area in which they are living; the seasonal flows of labour for horticulture for example.

The second area of research is related more directly to permanent internal and external migration. Research areas raised include :

(1) Examining the categories of people migrating (both emigration and immigration). Categories include nationality, occupation, age, sex, race, wealth and whether the migration is permanent or temporary.

(2) Factors behind the migration, e.g. job prospects, wages (both gross and net), political climate and social reasons such as family or refugee status.

(3) An examination of the job related categories and market factors affecting people who decline to migrate as well as those who do migrate.

(4) What has been the social impact on communities of migration (both internal and external)?

(5) The way migration has affected individuals - has it been better or worse than expected? Has their position improved?

(6) The construction of a regional matrix of internal migration, especially for young people would be useful. Is there a relationship between migration flows in such a matrix and changes in industry; do different age groups respond differently to industry shutdowns, etc.?

(7) How do we define migrant labour? Do we need to make distinctions between internal and external migration? Are there different characteristics between those 2 flows?

(8) What are the differences in the characteristics of ethnic migrant labour? What is the precise nature of the difference between migrants from say the Pacific Islands and the United Kingdom? Is there a difference between Maori migrants to the cities and Pacific Island migrants? 